\title{
PENGARUH DISIPLIN KERJA DAN KOMPENSASI TERHADAP KINERJA PETUGAS PENYAPU KEBERSIHAN DINAS LINGKUNGAN HIDUP KABUPATEN INDRAMAYU
}

\author{
The Effect Of Working Discipline And Compensation Towards Performance Of Cleanlands Of \\ Clean Environments Of Indramayu Regency
}

\author{
Riko $^{(1)}$, Sumardi HR ${ }^{(2)}$, Fitria Damayanti (3) \\ riko.cahaya28@gmail.com; Sumardi.hr@unwir.ac.id; fitria.damayanti@unwir.ac.id \\ Manajemen FE, Universitas Wiralodra
}

\begin{abstract}
Abstrak
Penelitian ini bertujuan untuk mengetahui seberapa besar pengaruh Disiplin Kerja dan Kompensasi Terhadap Kinerja Petugas Penyapu Kebersihan Dinas Lingkungan Hidup Kabupaten Indramayu. Penelitian ini menggunakan metode Deskriptif Asosiatif. Data pada penelitian ini diperoleh dengan observasi, wawancara dan menggunakan pernyataan angket yang dibagikan kepada Pimpinan dan 50 Petugas Penyapu Kebersihan Dinas Lingkungan Hidup Kabupaten Indramayu. Pemrosesan data dianalisis menggunakan analisis Korelasi berganda.

Hasil dari penelitian menunjukan bahwa Kinerja Petugas Penyapu Kebersihan Dinas Lingkungan Hidup Kabupaten Indramayu termasuk dalam kategori Baik. Disiplin Kerja Petugas Penyapu Kebersihan Dinas Lingkungan Hidup Kabupaten Indramayu termasuk dalam kategori Baik. Kompensasi Petugas Penyapu Kebersihan Dinas Lingkungan Hidup Kabupaten Indramayu termasuk dalam kategori Baik. Disiplin Kerja berpengaruh langsung dan positif terhadap Kinerja Petugas Penyapu Kebersihan Dinas Lingkungan Hidup Kabupaten Indramayu dengan kategori sangat rendah. Kompensasi berpengaruh langsung dan positif terhadap Kinerja Petugas Penyapu Kebersihan Dinas Lingkungan Hidup Kabupaten Indramayu dengan kategori rendah. Disiplin Kerja dan Kompensasi berpengaruh langsung dan positif terhadap Kinerja Petugas Penyapu Kebersihan Dinas Lingkungan Hidup Kabupaten Indramayu dengan kategori rendah.
\end{abstract}

Kata Kunci : Disiplin Kerja, Kompensasi dan Kinerja.

\begin{abstract}
This study aims to find out how much the influence of Work Discipline and Compensation on the Performance of Sweeper Officers in the Environmental Service Office of Indramayu Regency. This research uses the Associative Descriptive method. The data in this study were obtained by observation, interview and using a questionnaire statement that was distributed to the leadership and 50 cleaning officers of the Environmental Service Office of Indramayu Regency. Data processing was analyzed using multiple correlation analysis.

The results of the study showed that the performance of the Sweeper Officers of the Environmental Services Office of
\end{abstract}

the Indramayu Regency was included in the Good category. The Work Discipline of the Sweeper Officers for the Cleaning of the Environment Office of Indramayu Regency is included in the Good category. Compensation for the Sweeper Officers of the Environmental Service Office of the Indramayu Regency is included in the Good category. Work Discipline has a direct and positive effect on the Performance of Sweeper Officers in the Environmental Services Office of the Indramayu Regency with a very low category. Compensation has a direct and positive effect on the Performance of Sweeper Officers in the Environmental Services Office of the Indramayu Regency in the low category. Work Discipline and Compensation have a direct and positive effect on the Performance of Sweeper Officers in the Environmental Services Office of the Indramayu Regency in the low category.

Keywords: Work Discipline, Compensation and Performance

\section{PENDAHULUAN}

Persampahan merupakan salah satu permasalahan yang ada dalam melaksanakan pembangunan di masyarakat, menurut Undang Undang Nomor 18 tahun 2008 tentang Pengelolaan Sampah menyebutkan bahwa sampah telah menjadi permasalahan nasional sehingga pengelolaannya perlu dilakukan secara komprehensif dan terpadu dari hulu ke hilir agar memberikan manfaat secara ekonomi, sehat bagi masyarakat, dan aman bagi lingkungan, serta dapat mengubah perilaku masyarakat.

Tujuan utama dari suatu organisasi pemerintah adalah menjalankan kebijakan yang 
Riko, Sumardi HR, Fitria Damayanti

diberikan oleh pemerintah Indonesia agar dapat bersaing dengan negara maju. Setiap organisasi pemerintah dituntut untuk dapat mengoptimalkan sumber daya manusia dan bagaimana sumber daya manusia dikelola. Pengelolaan sumber daya manusia dimulai dari proses rekruitmen, training sampai proses maintainnya. Pengelolaan sumber daya manusia yang harus matang harus dimulai dari awal karena nantinya akan sangat menentukan kelangsungan organisasi.

Kinerja karyawan merupakan hasil kerja yang dinilai dari segi kualitas maupun kuantitas yang dicapai seorang karyawan dalam melaksanakan tugasnya sesuai dengan tanggung jawab yang diberikan kepadanya. Kinerja yang baik adalah kinerja yang optimal, yaitu kinerja yang sesuai standar organisasi dan mendukung tercapainya tujuan organisasi. Kinerja dari seorang karyawan merupakan hal yang bersifat individual, karena setiap karyawan memiliki kemampuan sendiri dalam menyelesaikan tugasnya. Seorang karyawan dikatan berhasil melakukan pekerjaannya jika mampu menyelesaikan tanggungjawab tugasnya dengan baik sesuai waktu yang telah ditetapkan. Kinerja karyawan merupakan suatu hal yang penting bagi sebuah instansi/organisasi karena akan berpengaruh pada kemajuan suatu organisasi dalam mencapai tujuan kegiatan khususnya sektor persampahan/kebersihan yang ada di Dinas Lingkungan Hidup Kabupaten Indramayu. Kualitas kinerja karyawan/petugas penyapu kebersihan Dinas Lingkungan Hidup
Kabupaten Indramayu dengan melihat dari mutu pekerjaan yang dihasilkan melalui proses yang mendekati kesempurnaan, untuk mengukur kinerja karyawan/petugas penyapu kebersihan dilihat dari lokasi penyapuan yang dapat diselesaikan dengan tepat waktu.

Penelitian sebelumnya telah membuktikan bahwa; Disiplin kerja berpengaruh terhadap kinerja pegawai, hal ini di buktikan oleh hasil penelitian yang dilakukan oleh Ali Wairooy yang berjudul Pengaruh Disiplin Kerja dan Kompensasi Terhadap Kinerja Karyawan pada PT. Pertamina (Persero), Tbk. Pemasaran Region VII Makassar. Kompensasi berpengaruh terhadap kinerja pegawai, hal ini dibuktikan oleh penelitian yang dilakukan Ananta Dwikristianto Satedjo dan Sesilya Kempa, dengan judul Pengaruh Kompensasi Dan Disiplin Kerja Terhadap Kinerja Karyawan PT. Modern Widya Tehnical Cabang Jayapura. Disiplin Kerja dan Kompensasi berpengaruh terhadap kinerja pegawai, hal ini dibuktikan oleh penelitian yang dilakukan Sisilia Naibaho Dkk, dengan judul Pengaruh Disiplin dan Kompensasi Terhadap Kinerja Karyawan Pada RSUP Prof. Dr. R.D. Kandou, Manado.

\section{TINJAUAN PUSTAKA}

1. Kinerja

Menurut Anwar prabu mangkunegara (2015:67) mengungkapkan Kinerja pegawai adalah hasil kerja secara kualitas dan kuantitas yang dicapai oleh seorang pegawai dalam melaksanakan tugasnya sesuai dengan tanggung jawab yang di berikan kepadanya. 
Riko, Sumardi HR, Fitria Damayanti

Menurut pendapat ahli tersebut peneliti memberi makna bahwa kinerja merupakan hasil kerja yang dicapai oleh seorang pegawai/karyawan dalam melaksanakan tugasnya dengan penuh tanggungjawab.

Menurut Colquit dalam Kasmir (2015:183) mengungkapkan Kinerja pegawai adalah nilai dari seperangkat perilaku pegawai yang berkontribusi, baik secara positif atau negatif terhadap pemenuhan tujuan organisasi. Menurut pendapat ahli tersebut peneliti memberi makna bahwa kinerja merupakan nilai dari pegawai yang berkontribusi untuk tujuan organisasi baik secara positif maupun negatif.

Menurut amstrong dan baron dalam buku irham fahmi (2014:127) mengungkapkan Kinerja adalah merupakan hasil pekerjaan yang mempunyai hubungan kuat dengan tujuan strategis organisasi, kepuasan konsumen dan memberikan kontribusi ekonomi. Menurut pendapat ahli tersebut peneliti memberi makna bahwa kinerja merupakan hasil pekerjaan dengan tujuan strategis organisasi dan memberikan kontribusi ekonomi serta kepuasan konsumen.

Dari ketiga pendapat para ahli di atas maka peneliti dapat mensintesiskan bahwa kinerja pegawai adalah hasil kerja pegawai secara kualitas dan kuantitas terhadap pemenuhan tujuan organisasi, kepuasan konsumen dan memberikan kontribusi ekonomi dalam melaksanakan tugasnya sesuai dengan tanggung jawab yang di berikan kepadanya. Menurut Kasmir (2015: 208), indikator kinerja adalah sebagai berikut : 1. Kualitas (mutu) 2. Kuantitas (jumlah) 3. Waktu 4. Penekanan biaya 5. Pengawasan 6. Hubungan antar karyawan

\section{Disiplin Kerja}

Menurut Singodimedjo dalam buku Edy Sutrisno (2017:86) Disiplin adalah sikap kesediaan dan kerelaan seseorang untuk mematuhi dan menaati norma-norma peraturan yang berlaku di sekitarnya. Menurut pendapat ahli tersebut peneliti memberi makna bahwa disiplin kerja merupakan sikap kesediaan dan kerelaan dalam mematuhi peraturan yang ada.

Menurut Kasmir (2015:193) Disiplin Kerja merupakan usaha karyawan untuk menjalankan aktivitas kerjanya secara bersungguh-sungguh. Menurut pendapat ahli tersebut peneliti memberi makna bahwa disiplin kerja merupakan usaha karyawan dalam bekerja secara bersungguhsungguh.

Menurut Keith Davis dalam buku Anwar Prabu Mangkunegara (2016:129) Disiplin kerja adalah sebagai pelaksanaan manajemen untuk memperteguh pedoman-pedoman organisasi. Menurut pendapat ahli tersebut peneliti memberi makna bahwa disiplin kerja adalah melaksanakan manajemen dengan memperteguh pedoman yang ada.

Dari ketiga pendapat para ahli di atas maka peneliti dapat mensintesiskan bahwa disiplin kerja adalah sikap kesediaan dan/atau kerelaan seseorang untuk menjalankan pekerjaannya serta menaati peraturan yang ada dalam memperteguh pedoman-pedoman organisasi. IndikatorIndikator disiplin kerja menurut Hasibuan, Malayu S.P (2012:194): 1. Tujuan dan Kemampuan 2. Tingkat Kewaspadaan Karyawan 3. Ketaatan pada standar kerja 4. Ketaatan pada peraturan kerja 5. Etika kerja.

3. Kompensasi

Menurut Arif Yusuf Hamali (2017:78) Kompensasi dimaksudkan sebagai balas jasa 
Riko, Sumardi HR, Fitria Damayanti

(reward) perusahaan terhadap pengorbanan waktu, tenaga dan pikiran yang telah diberikan karyawan kepada perusahaan. Menurut pendapat ahli tersebut peneliti memberi makna bahwa kompensasi adalah balas jasa (reward) yang diberikan oleh perusahaan/organisai kepada karyawan.

Menurut Handoko dalam Edy Sutrisno (2009:183) kompensasi adalah segala sesuatu yang diterima oleh karyawan sebagai balas jasa untuk kerja mereka. Menurut pendapat ahli tersebut peneliti memberi makna bahwa kompensasi adalah sesuatu yang diterima oleh karyawan atas usaha/kerja mereka.

Menurut Kasmir (2015:233) kompensasi merupakan balas jasa yang diberikan perusahaan kepada karyawanya, baik yang bersifat keuangan maupun non keuangan. Menurut pendapat ahli tersebut peneliti memberi makna bahwa kompensasi merupakan balas jasa yang diterima oleh karyawan baik berupa keuangan maupun non keuangan.

Dari ketiga pendapat para ahli diatas, peneliti dapat mensintesiskan bahwa kompensasi merupakan balas jasa (reward) yang diberikan perusahaan/organisasi kepada karyawan baik bersifat keuangan maupun non keuangan atas pengorbanan waktu, tenaga dan pikiran untuk bekerja terhadap perusahaan/organisasi tersebut. Indikator Kompensasi Menurut Kasmir (2015:251) : 1. Pendidikan 2. Pengalaman 3. Beban Pekerjaan dan Tanggung Jawab 4. Jabatan 5. Jenjang Kepangkatan Atau Golongan 6. Prestasi Kerja

\section{METODE PENELITAN}

Metode yang digunakan dalam, penelitian ini adalah metode deskriptif dan metode asosiatif dengan teknik analisis data menggunakan Analisis Korelasi Ganda.

Data yang dipergunakan adalah data primer berupa seperangkat format instrument penelitian yang terdiri dari angket berupa penilaian pimpinan dan tanggapan petugas penyapu kebersihan yang dipergunakan untuk mengumpulkan data; variabel Kinerja, Disiplin Kerja dan Kompensasi yang diisi oleh pimpinan Dinas Lingkungan Hidup Kabupaten Indramayu dan Petugas Penyapu Kebersihan.

Populasi dari Petugas Kebersihan di Dinas Lingkungan Hidup Kabupaten Indramayu berjumlah 380 orang akan tetapi peneliti hanya diberikan sampel diwilayah perkotaan saja yaitu petugas penyapu kebersihan 60 orang Namun pada penelitian ini yang dijadikan objeknya adalah 60 orang dikurangi 10 orang untuk dijadikan uji validitas dan realibilitas dan sisa nya 50 orang untuk sampel.

Adapun variabel dan indikator pada penelitian ini tergambar pada Tabel 1. 
Tabel 1

Variabel Indikator Penelitian

\begin{tabular}{|c|c|c|c|}
\hline Variabel & Indicator & Skala & referensi \\
\hline Kinerja $(\mathrm{Y})$ & $\begin{array}{l}\text { Kualitas (mutu) } \\
\text { Kuantitas (jumlah) } \\
\text { Waktu } \\
\text { Penekanan biaya } \\
\text { Pengawasan } \\
\text { Hubungan antar karyawan }\end{array}$ & Likert & $\begin{array}{l}\text { Indikator } \\
\text { Kasmir } \\
(2015: 208)\end{array}$ \\
\hline Disiplin Kerja $\left(\mathrm{X}_{1}\right)$ & $\begin{array}{l}\text { Tujuan Kemampuan } \\
\text { Tingkat Kewaspadaan Karyawan } \\
\text { Ketaatan pada standar kerja } \\
\text { Ketaatan pada peraturan kerja } \\
\text { Etika kerja }\end{array}$ & Likert & $\begin{array}{l}\text { Indikator } \\
\text { Hasibuan, } \\
\text { Malayu S.P } \\
(2012: 194) \\
\end{array}$ \\
\hline Kompensasi $\left(\mathrm{X}_{2}\right)$ & $\begin{array}{l}\text { Pendidikan } \\
\text { Pengalaman } \\
\text { Beban Pekerjaan dan Tanggung Jawab } \\
\text { Jabatan } \\
\text { Jenjang Kepangkatan atau Golongan } \\
\text { Prestasi Kerja }\end{array}$ & Likert & $\begin{array}{l}\text { Indikator } \\
\text { Kasmir } \\
(2015: 251)\end{array}$ \\
\hline
\end{tabular}

\section{HASIL DAN PEMBAHASAN}

Valid tidaknya butir instrumen diuji terlebih dahulu signifikansi koefisien korelasinya dengan cara membandingkan dengan nilai $r_{\text {tabel }}$. Kriteria keputusan ditetapkan bahwa butir instrumen dikatakan valid jika $r$ observasi lebih besar dari pada $r_{\text {tabel }} 0.632$ seperti yang tergambar pada Tabel 2.

Tabel 2

Validitas variabel

\begin{tabular}{lllllll}
\hline \multirow{2}{*}{ Variabel } & \multirow{2}{*}{ Reritical } & R Rount & \multicolumn{3}{c}{ Nilai } & \multirow{2}{*}{ Exp. } \\
\cline { 3 - 6 } & R below & Rupper & Min & Max & \\
\hline Kinerja & 0.632 & 0.642 & 0.873 & 25 & 120 & Valid \\
\hline Disiplin Kerja & 0.632 & 0.641 & 0.852 & 24 & 104 & Valid \\
\hline Kompensasi & 0,632 & 0,640 & 0,858 & 24 & 120 & \multirow{2}{*}{ Valid } \\
\hline
\end{tabular}

Kriteria reliabilitas mempergunakan koefisien reliabilitas Alpha dari Cronbach dengan cara menghitung masing masing reliabilitas ( $\mathrm{r}$ hitung) tiap variable dan memasukan hasilnya kedalam kategori yang telah ditetapkan (Alpha Cronbach) Tabel 3.

Tabel 3

reliabilitas Alpha Cronbach

\begin{tabular}{lccccc}
\hline \multirow{2}{*}{ Variabel } & \multirow{2}{*}{\begin{tabular}{r}
$<0,50$ \\
\cline { 3 - 5 }
\end{tabular}} & & $\begin{array}{c}0,51-0,70 \\
\text { Rendah } \\
\text { Moderat }\end{array}$ & $\begin{array}{c}0,71-0,90 \\
\text { Tinggi }\end{array}$ & $\begin{array}{c}>0,91 \\
\text { Sempurna }\end{array}$ \\
\hline Kinerja & 0,961 & & & $\mathrm{X}$ \\
\hline Disiplin Kerja & 0,991 & & $\mathrm{X}$ \\
\hline Kompensasi & 0,976 & & & $\mathrm{X}$ \\
\hline
\end{tabular}

Penelitian ini mempunyai tiga variabel yaitu variabel; Kinerja (Y) sebagai variable terikat, sedangkan Disiplin Kerja $\left(\mathrm{X}_{1}\right)$ dan Kompensasi $\left(\mathrm{X}_{2}\right)$ sebagai variabel bebas. Konstalasi penelitian simultan (berganda) yang tergambar pada Gambar 1.

Gambar 1

Konstalasi Penelitian

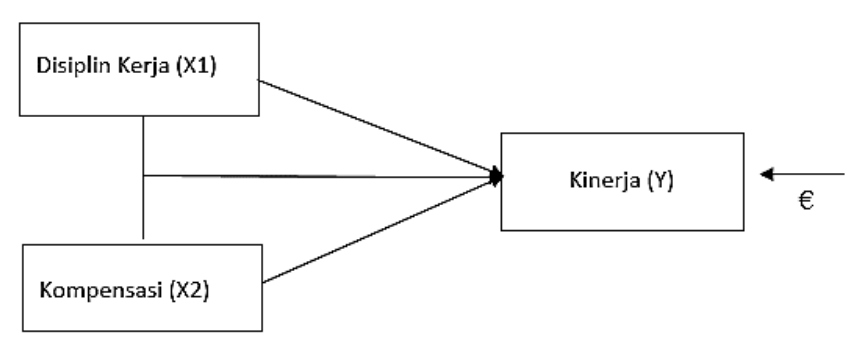

Responden adalah petugas penyapu kebersihan Dinas Linkungan Hidup Kabupaten Indramayu memiliki latar belakang pendidikan seperti yang pada Tabel 4 .

Tabel 4

latar belakang pendidikan responden

\begin{tabular}{clc}
\hline No. & $\begin{array}{c}\text { Latar belakang } \\
\text { pendidikan }\end{array}$ & Jumlah \\
\hline 1 & SD & 17 \\
\hline 2 & SMP & 20 \\
\hline 3 & SMA & 13 \\
\hline
\end{tabular}

Tabel 5

Deskripsi data 
Riko, Sumardi HR, Fitria Damayanti

\begin{tabular}{|c|c|c|c|c|c|c|c|c|c|c|c|c|c|c|c|c|}
\hline variable & \multicolumn{6}{|c|}{ Kinerja } & \multicolumn{5}{|c|}{ Disiplin Kerja } & \multicolumn{5}{|c|}{ Kompensasi } \\
\hline Indikator & 1 & 2 & 3 & 4 & 5 & 6 & 1 & 2 & 3 & 4 & 5 & 1 & 2 & 3 & 4 & 5 \\
\hline $\begin{array}{l}\text { Jumlah } \\
\text { butir }\end{array}$ & 2 & 2 & 2 & 2 & 2 & 2 & 2 & 2 & 2 & 2 & 2 & 2 & 2 & 2 & 2 & 2 \\
\hline $\begin{array}{l}\text { Rata2 } \\
\text { indikator }\end{array}$ & $\begin{array}{c}40 \\
6\end{array}$ & $\begin{array}{c}41 \\
2\end{array}$ & \begin{tabular}{c|c}
40 \\
0
\end{tabular} & $\begin{array}{c}40 \\
1\end{array}$ & $\begin{array}{c}39 \\
9\end{array}$ & $\begin{array}{r}37 \\
3\end{array}$ & $\begin{array}{c}42 \\
3 \\
\end{array}$ & \begin{tabular}{c|}
41 \\
2 \\
\end{tabular} & \begin{tabular}{c|}
40 \\
5
\end{tabular} & 412 & $\begin{array}{c}40 \\
8\end{array}$ & $\begin{array}{c}40 \\
6\end{array}$ & $\begin{array}{c}41 \\
3 \\
\end{array}$ & \begin{tabular}{l|l}
38 \\
9
\end{tabular} & 392 & $\begin{array}{c}37 \\
8\end{array}$ \\
\hline $\begin{array}{l}\text { Rerata } \\
\text { Variabel }\end{array}$ & \multicolumn{6}{|c|}{398,5} & \multicolumn{5}{|c|}{412} & \multicolumn{5}{|c|}{391} \\
\hline $\begin{array}{l}\text { Indikator } \\
\text { terendah }\end{array}$ & \multicolumn{6}{|c|}{$\begin{array}{l}\text { 6. Hubungan Antar Karyawan } \\
\text { (373) }\end{array}$} & \multicolumn{5}{|c|}{$\begin{array}{l}\text { 3. Ketaatan pada standar } \\
\text { keria (405) }\end{array}$} & \multicolumn{5}{|c|}{ 6. Prestasi Kerja (367) } \\
\hline $\begin{array}{l}\text { Indikator } \\
\text { tertinggi }\end{array}$ & \multicolumn{6}{|c|}{ 3. Kuantitas (412) } & \multicolumn{5}{|c|}{$\begin{array}{l}\text { 1. Tujuan Kemampuan } \\
\text { (423) }\end{array}$} & \multicolumn{5}{|c|}{ 2. Pengalaman (413) } \\
\hline $\begin{array}{l}\text { Butir } \\
\text { (item) } \\
\text { terendah }\end{array}$ & \multicolumn{6}{|c|}{$\begin{array}{l}\text { 11. Kerjasama antar petugas } \\
\text { penyapu kebersihan (186) }\end{array}$} & \multicolumn{5}{|c|}{$\begin{array}{l}\text { 9. Suasana pekerjaan antar } \\
\text { sesama karyawan (199) }\end{array}$} & \multicolumn{5}{|c|}{$\begin{array}{l}\text { 12. Kompensasi bagi kinerja } \\
\text { karyawan yang baik (183) }\end{array}$} \\
\hline $\begin{array}{l}\text { Butir } \\
\text { (item) } \\
\text { tertingai }\end{array}$ & \multicolumn{6}{|c|}{$\begin{array}{l}\text { 3. Jumlah personil petugas } \\
\text { penyapu kebersihan (208) }\end{array}$} & \multicolumn{5}{|c|}{$\begin{array}{l}\text { 1. Kemampuan Karyawan } \\
\text { (216) }\end{array}$} & \multicolumn{5}{|c|}{$\begin{array}{l}\text { 3. Jangka waktu bekerja ses } \\
\text { kompensasi (209) }\end{array}$} \\
\hline
\end{tabular}

Analisis Korelasi

1. Analisis Korelasi Disiplin Kerja Terhadap Kinerja

Hasil perhitungan korelasi Disiplin Kerja terhadap Kinerja menggunakan rumus Produk Moment Pearson sebagai berikut $r_{\text {hitung }}=0,133$

Artinya disiplin kerja berpengaruh terhadap kinerja sebesar 0,133 termasuk kategori Sangat Rendah.

2. Analisis Korelasi Kompensasi Terhadap Kinerja

Hasil perhitungan korelasi Kompensasi terhadap Kinerja menggunakan rumus Produk Moment Pearson sebagai berikut $r_{\text {hitung }}=0,298$

Artinya kompensasi berpengaruh terhadap kinerja sebesar 0,298 termasuk kategori Rendah.

3. Analisis Korelasi Disiplin Kerja Terhadap Kompensasi

Hasil perhitungan korelasi Disiplin Kerja terhadap Kompensasi menggunakan rumus Produk Moment Pearson sebagai berikut $r_{\text {hitung }}=0,110$
Artinya disiplin kerja berpengaruh terhadap kompensasi sebesar 0,110 termasuk kategori Sangat Rendah.

4. Analisis Koefisien Korelasi Berganda

Korelasi ganda merupakan angka yang menunjukan arah dan kuatnya hubungan antara dua variabel independen secara bersama-sama atau lebih dari satu variabel independen. Jadi analisis korelasi berganda bertujuan untuk mengetahui koefisien korelasi antara variabel Disiplin Kerja (X1) dan Kompensasi (X2) terhadap Kinerja (Y) secara simultan atau bersama-sama. Hasil perhitungan koefisien korelasi berganda adalah 0,315

Artinya pengaruh Disiplin Kerja dan Kompensasi terhadap Kinerja sebesar 0,315 yang termasuk kategori Rendah.

Gambar 2

Analisis Penelitian

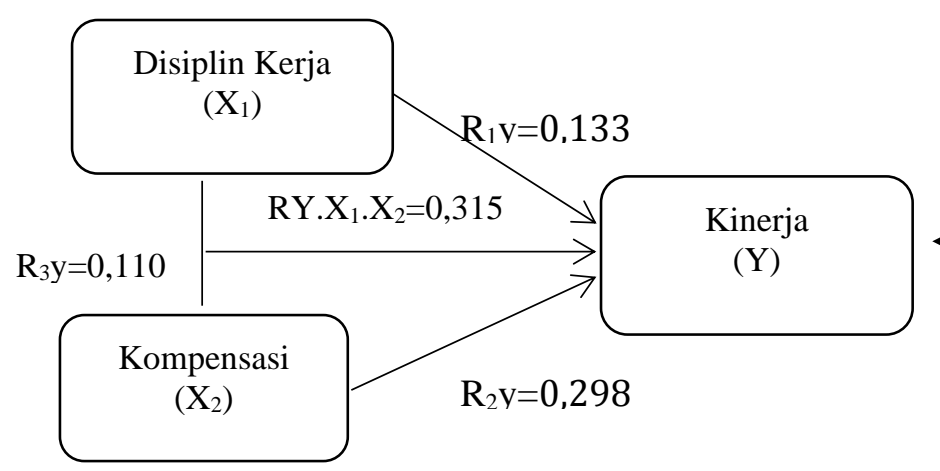

KESIMPULAN DAN SARAN

Dari hasil uraian diatas, serta hasil pembahasan yang peneliti lakukan tentang Pengaruh Disiplin Kerja dan Kompensasi terhadap Kinerja Petugas Penyapu Kebersihan Dinas Lingkungan Hidup Kabupaten Indramayu, 
Riko, Sumardi HR, Fitria Damayanti

maka peneliti mengambil kesimpulan sebagai berikut :

1. Disiplin Kerja Petugas Penyapu Kebersihan Dinas Lingkungan Hidup Kabupaten Indramayu termasuk dalam kategori Baik.

2. Kompensasi Petugas Penyapu Kebersihan Dinas Lingkungan Hidup Kabupaten Indramayu termasuk dalam kategori Baik.

3. Kinerja Petugas Penyapu Kebersihan Dinas Lingkungan Hidup Kabupaten Indramayu termasuk dalam kategori Baik.

4. Pengaruh Disiplin Kerja terhadap Kinerja Petugas Penyapu Kebersihan Dinas Lingkungan Hidup Kabupaten Indramayu termasuk dalam kategori sangat rendah.

5. Pengaruh Kompensasi terhadap Kinerja Petugas Penyapu Kebersihan Dinas Lingkungan Hidup Kabupaten Indramayu termasuk dalam kategori rendah.

6. Pengaruh Disiplin Kerja dan Kompensasi terhadap Kinerja Petugas Penyapu Kebersihan Dinas Lingkungan Hidup Kabupaten Indramayu termasuk dalam kategori rendah.

Berdasarkan hasil kesimpulan diatas, peneliti mengemukakan beberapa saran antara lain sebagai berikut :

1. Disiplin Kerja Petugas Penyapu Kebersihan Dinas Lingkungan Hidup Kabupaten Indramayu perlu ditingkatkan ketaatan pada standar kerja sehingga dapat menyelesaikan pekerjaannya lebih baik lagi.
2. Kompensasi

Dinas Lingkungan Hidup Kabupaten Indramayu sebaiknya lebih memperhatikan terhadap petugas penyapu kebersihan yang berprestasi baik dengan memberikan reward (penghargaan). Hal ini dapat meningkatkan kinerjanya lebih baik lagi.

3. Kinerja

Petugas Penyapu Kebersihan Dinas Lingkungan Hidup Kabupaten Indramayu perlu menigkatkan kinerja dalam hal mencapai target kerja serta hubungan antar karyawan untuk dapat menyelesaikan pekerjaan.

\section{DAFTAR PUSTAKA}

Kasmir. (2016). Manajemen Sumber Daya Manusia. Jakarta. Teori dan Praktik;

Mangkunegara, Anwar Prabu. (2016). Manajemen Sumber Daya Manusia Pemahaman. Bandung;

Hamali, Arif Yusuf. (2018). Pemahaman Manajemen Sumber Daya Manusia. Jakarta. Strategi Mengelola Karyawan; Sutrisno, Edy. (2017). Manajemen Sumber Daya Manusia. Jakarta.

Fahmi, Irham. (2014). Perilaku Organisasi. Bandung. Teori, Praktik dan Kasus.

Hasibuan, Malayu S.P. 2012. Manajemen Sumber Daya Manusia. Cetakan ke delapan belas. Jakarta: PT Bumi Aksara. 
Sugiyono. 2015. Statistik Untuk Penelitian.

Bandung: CV Alfabeta.

Sugiyono. 2017. Metodologi Penelitian

Kuantitatif, Kualitatif dan R\&D.

Bandung: CV Alfabeta.

Wairooy, Ali. (2017). Jurnal Pemikiran Ilmiah dan Pendidikan Administrasi

Perkantoran Vol. 4 No.1. Jurnal

Administrative.

https://ejournal.unsrat.ac.id/index.php/jbi e/article/viewFile/12560/12132

Satedjo, Ananta Dwikristianto dan Kempa Sesilya. (2017). Jurnal Agora Vol. 5 No.3.

ojs.unm.ac.id/administrare/article/downl $\underline{\mathrm{oad} / 3442 / 1939}$

Naibaho, Sisilia Dkk. (2017). Jurnal Berkala Ilmiah Efisiensi Vol. 16 No.02.

https://ejournal.undiksha.ac.id/index.php /JJM/article/download/6781/4629

Purnama, Catherine. (2016). Jurnal Agora Vol.4 No.02.

jurnal.untad.ac.id/jurnal/index.php/Feko n/article/download/10858/8517

Pertiwi, Fauziah Intan. (2015). Jurnal eProceeding of Management Vol. 2 No.3. eprints.walisongo.ac.id/6266/1/1024110 26.pdf 